\title{
Peripheral Nerve
}

National Cancer Institute

\section{Source}

National Cancer Institute. Peripheral Nerve. NCI Thesaurus. Code C12768.

Any nerve outside the brain or spinal cord that connects with peripheral receptors or effectors. 